\title{
Employing Problem Based Learning System in Advancing Communication Skills Proficiency in Professional Communication for Engineering Undergraduates
}

\author{
Sree Devi Jasti \\ Dept. of Humanities \& Sciences \\ Vidya Jyothi Institute of Technology \\ Hyderabad, Telangana \\ Mobile No: 9985080771 \\ Email: sreejasti99@gmail.com
}

\section{ABSTRACT:}

Problem Based Learning is a Teaching-Learning Methodology, which has been employed fruitfully to enhance learning in diverse situations and at numerous levels around the world. It has been proved by some studies, it's worth as an effective learning technique in learning different courses including effective language skills in English. PBL can augment the learners' proficiency in effective professional communication skills and lessen their complications for communication. The purpose of the research is to identify if, Problem Based Learning can be applied, to enrich professional communication skills in English while concurrently nurturing the development of Content Knowledge, Problem-Solving, Critical Thinking, Collaboration, and Self-

Directed learning skills. This paper reports some of the findings of the study conducted on the use of Problem Based Learning, in the PDBS class on enhancing Professional English Language Communication Skills at Vidya Jyothi Institute of Technology an Engineering College. It was a descriptive study conducted in Vidya Jyothi Institute of Technology college for the third year Electronics and Communication Engineering (ECE) students. The experimental group of the study includes 64 students of section-C of the third year ECE, involved in learning through PBL and 64 students of section-D students of the same third year ECE as the non-experimental group, here both the sections were taking the Personality Development \& Behavioral Skills (PDBS) Course in English. The Data was collected through a questionnaire answered by the students of both the sections C\&D of III-ECE. The study found that students were well aware of the methodology of PBL, further the students also enjoyed learning in the procedure implemented through Problem Based Learning. The study concluded with a comprehensive application of PBL in the use of this technique with the experimental group and its positive outcome in the development of effective communication skills, critical thinking and effective presentation of their ideas in comparison to the nonexperimental group where the students had an awareness of the PBL methodology of teaching and learning. The limitations of

\author{
Dr A. Pavani \\ Dept. of Humanities \& Sciences \\ KL University, Vaddeswaram, \\ Guntur, AP \\ Mobile No: 9494239560 Email: \\ pavanilinguist@kluniversity.in
}

the study and suggestions for further research are offered at the end of the paper.

Key words: Problem Based Learning, Professional Communication Skills, Improved Content Knowledge

\section{REVIEW OF RELATED LITERATURE}

Problem Based Learning is an inclusive approach of teaching, where students are kept in a stimulating situation, they are put to some unassertive and free problems (Barrows, 2000; Silver, $2004 \&$ Rattanavich, 2008). The prerequisite is that, they have to find solution for the problem given to their group by working in teams (the team size is 4 students in each team). The responsibility of the lecturer is curtailed as a guide and facilitator. In this process of learning both curriculum and process, increases the students' acquisition of Critical Knowledge, Self-directed Learning Strategies, Problem Solving Proficiency and Team Participation Skill (Rattanavich 2008). PBL has been defined by the Classical Approach as, small and permanent groups of students working with a teacher on a new case with inputs given in every three class sessions. The group receives on the first day a case study and commences to analyze the primary data with the assistance of the teacher, the group decides on the problems to be addressed and allocates the research assignment among the team members. The students, in the next class, share their analysis, receive extra information, and resume their search. The students bring the team closure to the case in the third-class session, this is when the groups pull together their knowledge and prepare the final report. This definition of PBL as per the Classical Approach has been redefined and modified in various ways for different courses (Herreid, 2003). Sonmez and Lee (2003) have offered a functional description which is more applicable to Professional Education defining PBL as: PBL is an instructional approach that confronts students both individually or in a group to pursue solutions to the real world problems, compared to learning through the traditional learning from lectures or textbooks. PBL also engrosses students in developing their skills as Selfdirected Learners. 
As has been stated, Problem Based Learning (PBL) is mostly applied by arranging the class into minor groups, lecturer being the facilitator specifies a few moderately appropriate problems to students and pilots them with minimum inputs, on how to confront the problems. Students slowly gain confidence with PBL, the guidance is further reduced as they gain experience. This process can be regulated by giving the students few worked examples during the initiation of their progress. The students can be challenged in the later stages with some lesser complex problems until they gain a significant proficiency to face more realistic problems. But many designers of PBL do not agree with Merrill and suggest that the students should be given realistic problems from the very beginning, however the lecturer should specify them with sufficient support at earlier stages and gradually it may be reduced as the students grow proficient in managing the problems.

The suggestion given by Silver in applying PBL is by using of white boards to help students scaffolding their problem solving depicted in Four Columns- the Facts Columns, the Ideas

Columns, the Learning Issues Column, and Action Plan Columns. The students are asked to record their progress on it. During the process the students should have a discourse on the problems, demarcate them in the light of their previous knowledge, then form a supposition, later they have to set their learning aims and also establish further learning. The students should be able to reflect on what has been learnt through the process, after classifying out the solutions, then they shall present their findings to the complete class.

As the PBL course features minimal teaching, the lecturer must be adept in handling PBL classes by creating ill-structured problems that would sustain students' interest for a few weeks, PBL advocates to go through the process of researching and creating problems that contain multiple solution paths in relevance to the Course Content. The process used by the lecturer to design a Problem-Based Learning experience for the students in the PBL method is like:

- Identifying a problem appropriate for the students,

- Linking the problem with the perspective of the students' sphere so that it presents reliable opportunities,

- Systematizing the subject around the problem,

- $\quad$ Providing the students responsibility for defining their learning experience,

- Generating interest and controversy to cause the learner to ask questions

- Making the problems open-ended and complex enough to require collaboration and thinking beyond recall.

- Planning to solve the problem,

- Inspiring cooperation by creating learning teams and

- Presuming all students to demonstrate the results of their learning through a product or performance.
So how does learning take place in the PBL approach when the students receive no instruction? In the PBL class, when the students work with each other to solve complicated and authentic problems, they are expected to be so absorbed in the tasks that they will not only increase their Content Knowledge but simultaneously enhance their Professional Communicative Skills and Thinking Skills as they shall communicate, reason, assess the problem(s) at hand and solve them. Watson (2001, p. 3) explains that in PBL, "students work with classmates to solve complex and authentic problems that help develop their Content knowledge as well as Problem-solving Skills, Reasoning Skills, Professional Communication Skills, and Self-assessment Skills". Thus, in a Problem-Based classroom, the process is crucial as that is where real learning actually takes place. The outcome is important too, and as learners acquire and develop the skills mentioned above, there will be opportunities for these learners to apply those skills across other disciplines in the long term.

PBL has its merits as it is a move towards professional training; it gets students ready for the real world, as students are exposed to the following challenges and skills (Tan, 2003):

- Teamwork

- Independent learning

- Professional Communication Skills

- Problem-solving Skills

- Interdisciplinary Learning

- Higher-order Thinking Skills

Since research in PBL in language courses are far and in between, this study, therefore, aims to address the gap in research on PBL in English language teaching-learning and in content-based language teaching-learning. To summarize, research done on PBL, several benefits have been highlighted, which include: (1) Language Skills, (2) Professional Communicative Skills, particularly among those who do not have much opportunity to speak up in a teacher-centered classroom; (3) Reading Skills; (4) Critical Thinking Skills; (5) Collaborative Learning, and (6) Social Skills. Along with these, as advocated by the approach and mentioned in the review, students are nurtured to become lifelong independent learners.

\section{OBJECTIVES OF THE STUDY}

The objectives of the study are to investigate the effects of PBL on:

1. Improved proficiency in Professional Communication by the students; and

2. Improved acquisition of course content by the students

The first objective is to enhance the students in the PBL group to acquire and improve their Professional Communication 
language skills. It was facilitated due to the amount of reading carried out for each task. The students will be exposed to problems relevant to the course content and as they read, gather $\&$ sort their data to solve the problems. If PBL is to be considered as an alternative to the traditional lecture approach in acquisition of effective professional communication skills and the course content by the students, the learning is more enhanced with PBL. This is achieved due to the students being engaged in self-learning instead of spoon-feeding by lectures, as lecturers in the PBL classroom do not give as many inputs as in the traditional method. The enhanced learning of the students in PBL, is because of the self 'discovery' of knowledge in PBL causing the students to retain it better than when they learn it via spoon-feeding from lecturers in the traditional approach.

\section{RESEARCH QUESTIONS}

To address the objectives of the study, the following research questions were formulated:

1. To what extent does the PBL approach enhance the students' Professional language proficiency?

2. Is there a difference in the extent of content learned by both the PBL and the non-PBL groups?

\section{METHODOLOGY}

\section{a. Subjects}

The subjects of the study were 128 third-year engineering undergraduate students enrolled in two sections of the PDBS class that has a Professional Communication Skills in its syllabus. Classes were scheduled twice a week, 55 minutes per session. Discussions, Class Activities and Group Presentations were carried out in conventional classrooms, using the Board, Computer and LCD Projector.

\section{b. Procedure}

The course had four sections; of them two sections were considered for the experiment. One of the classes, comprised 64 students, followed the PBL approach, while the other, again comprising 64 students, followed the traditional lecture and guided approach. The former formed the experimental group, while the latter the control group. The PBL class was further grouped into teams of four students. Everyone had the same lecturer, common notes, syllabus and course outlines. The lecturer was always present in class to note students' behavior and interaction. The PBL groups were given a problem on the first day of each new task and expected to present their findings to the class the following week. Presentations as well as a written report were submitted to the instructor a few days after the culmination of all presentations of a task.
Table 1 lists the areas covered during the 14week semester for the experimental and control groups.

Table 1. Distribution of topics per 2-week period for the course

\begin{tabular}{|l|l|}
\hline Weeks 1 \& & Introduction, Division of \\
2 & Groups and Pre-Tests \\
\hline $\begin{array}{l}\text { Weeks 3 \& } \\
4\end{array}$ & $\begin{array}{l}\text { English Professional } \\
\text { Communication Skills }\end{array}$ \\
\hline $\begin{array}{l}\text { Weeks 5 \& } \\
6\end{array}$ & Words and Lexical Structure \\
\hline $\begin{array}{l}\text { Weeks } 7 \& \\
8\end{array}$ & On Meaning \\
\hline $\begin{array}{l}\text { Weeks } 9 \& \\
10\end{array}$ & $\begin{array}{l}\text { Phrase, Clause and Sentence } \\
\text { structure }\end{array}$ \\
\hline $\begin{array}{l}\text { Weeks } 11 \& \\
12\end{array}$ & $\begin{array}{l}\text { Language in Context } \\
\text { (Communication) }\end{array}$ \\
\hline $\begin{array}{l}\text { Weeks 13 \& } \\
14\end{array}$ & Post-tests and Conclusion \\
\hline
\end{tabular}

The non-PBL group had lectures for each topic on the course outline and only one group assignment to be presented and submitted at the end of the semester. However, group work was assigned after the topic that had been lectured and discussed throughout the semester. Students in the non-PBL classes were also given sample literary pieces, in addition to those in the lecture notes of the Course, that the teacher discussed in class according to the topic of the week. The presentation and assignment followed the same format as the PBL group. However, the PBL group had to write comments and evaluations of the class at the end of the semester, particularly on the method adopted to learn and what they had learned. These were analyzed for themes that would support the empirical data of the study.

\subsection{Assessment of Research Objectives}

To answer Research Question 1, i.e. to determine the subjects' language progress both in reading and writing, with students of both PBL and non-PBL approaches having the following tests:

1. An English Proficiency Test that consisted of a carefully constructed cloze tests, suited to the level of the students (advanced) at the beginning and end of the semester. The cloze test was chosen to test students' reading skills that might have improved following the PBL tasks.

2. Essay writing of approximately 400 to 600 words, at the beginning of the semester (pre-test) and end post-test. The essays were graded for language and content, and subsequently the results of the two groups were evaluated, compared and contrasted 

according to the given marking scheme employed for the course.

To answer Research Question 2, that is acquisition of course content, the results of the final examination scores for both groups were analyzed for similarities and differences, bearing in mind that the PBL group followed a self-learning structure via solving meaningful tasks, while the non-PBL had traditional lectures.

\section{FINDING AND DISCUSSION}

Although evaluations of the PBL groups were varied (peer and teacher evaluations, interviews, observations, pre-tests and posttests), the discussion of the findings will only focus on the results of the pre-tests and post-tests of both groups for the cloze and essay, and the final examination scores. The pre-tests and post-tests were carried out to determine students' language improvements, while the final examination results were analyzed to see the differences in performances between the PBL and non-PBL groups in terms of course content, i.e., with and without traditional instructions. Since the language tests were administered before the Final examination, the results in the following section are also presented in this order.

\subsection{Pre- and Post-Test Scores of PBL and non-PBL Groups for the Cloze Tests}

This section presents and discusses the results of the pre- and post-test scores of the PBL and non-PBL groups, which are shown in Table 1. The mean scores of the cloze results of both groups at the beginning of the semester were 9.36 and 9.25 for the non-PBL and PBL groups, respectively. The difference is not that marked $(0.11)$ which indicates that from the outset, the two groups, more or less, were at par in terms of their language abilities. The t-test for each group showed significance at $\mathrm{p}<$ 0.005 .

Table 2. Performance of Experimental and Control Groups on the Cloze Test

\section{Experimental Group Pre-Test Post-Test}

\begin{tabular}{|c|c|c|c|c|}
\hline & \multicolumn{2}{|c|}{ Experimental Group } & \multicolumn{2}{|c|}{ Control Group } \\
\hline & Pre-Test & Post-Test & Pre-Test & Post-Test \\
\hline $\begin{array}{c}\text { Mean } \\
(/ 20)\end{array}$ & 9.36 & 13.35 & 9.25 & 10.70 \\
\hline $\mathrm{n}$ & 64 & 64 & 64 & 64 \\
\hline Std. dev. & 4.224 & 4.363 & 4.425 & 4.316 \\
\hline Std. error & .623 & .643 & .700 & .682 \\
\hline $\mathrm{r}$ & .848 & & .890 & \\
\hline $\mathrm{t}$ & -9.393 & & -2.931 & \\
\hline $\mathrm{df}$ & 45 & & 39 & \\
\hline
\end{tabular}

\begin{tabular}{|c|l|l|l|l|}
\hline $\begin{array}{c}\text { Sig. } \\
\text { (2tailed) }\end{array}$ & $.000 *$ & $.006^{*}$ & \\
\hline
\end{tabular}

*Significant difference

The results show that both the groups show improvement in the cloze test. Particularly, the PBL approach has had the post-test, the PBL group's mean score was 13.35, a difference of 3.99 from the pre-test. The non-PBL group, on the other hand, showed a mean score of 10.30 and a difference of 1.45 from the pre-test. The higher difference in mean score in the PBL group may be attributed to the extensive and critical reading students had to do on a variety of reading material in order to gather data to solve the PBL tasks. This was not done by the non-PBL group which received normal classroom instruction.

\subsection{The Written Tests}

The written tests, where students had to write on the same topic for both the pre- and post-tests, were given in the second and last week of the semester. The essays were evaluated by two teachers, to ensure scoring reliability, and were evaluated for language and organization, and content (topic sentence, explanation and relevant examples). Analysis of individual essays showed differences which were not marked enough, but when the results were combined according to the set categories of content and organization, the differences were clearer, as shown in Tables 3 and 4. In terms of language and organization, the essays were marked according to the overall language and structure of the essay, that is, in addition to a holistic scoring for language, the scoring also considered the presence of a clear introduction, a thesis or purpose statement, paragraphing of points, and a conclusion. Higher marks were awarded to students who showed efforts in using sub-topics to organize their essays. Lastly, content showed the presence of topic sentence/ideas, explanations and points which illustrated or elaborated the main points depicting, effective professional communication skills. T-tests were carried out for both groups; the results of the pre- and post-tests of the PBL group showed significance $(\mathrm{p}<0.005)$, while the non-PBL group was not significant $(\mathrm{p}>0.005)$.

Table 3. Accumulated results of pre and post essay writing of PBL subjects

\begin{tabular}{|c|c|c|c|}
\hline & Pre-Test & Post-Test & Difference \\
\hline Organization & 425 & 508 & 19.5 \\
\hline Content & 82 & 168 & 104 \\
\hline \multicolumn{4}{|c|}{$n=64 ; \mathrm{p}<0.005$ (significant) }
\end{tabular}

Table 4. Accumulated results of pre and post writing of nonPBL subjects

\begin{tabular}{|l|c|c|c|}
\hline \multicolumn{4}{|c|}{ Pre-Test Post-Test } \\
Difference & 420 & 505 & 20.2 \\
\hline Organization & 79 & 120 & 51.9 \\
\hline Content & $n=64 ; \mathrm{p}<0.005$ (non-significant)
\end{tabular}


The results were accumulated to show the differences in terms of content and organization, which did not show in the individual results, as mentioned. The tables showed that for both groups, none of the post-test scores are lower than the pretest scores for the two categories, which indicated improvements for both groups. For the PBL group, we can see that in terms of organization, the difference is slight at $19.5 \%$. The results stated thus far do not suggest marked improvements or differences between the groups. However, there is a marked difference in the content, in terms of the number of supporting points between the groups, which are $104 \%$ increase for the PBL group compared to $51.9 \%$ for the non-PBL group. Therefore, it would appear that students in the PBL group showed greater development in their content knowledge \& writing skills and were able to present more arguments in their essays to support their points. As in the cloze test results, the improvements could have been due to the readings students were subjected to as well as the critical discussion and presentation of their data to the group after the reading.

The statistical results for the writing tests are as follows:

Table 5. Performance of Experimental and Control Groups in Essay Writing Test

\begin{tabular}{|c|c|c|c|c|}
\hline & \multicolumn{2}{|c|}{ Experimental Group. } & \multicolumn{2}{|c|}{ Control Group } \\
\hline & Pre-Test & Post-Test & Pre-Test & Post-Test \\
\hline $\begin{array}{l}\text { Mean } \\
(/ 20)\end{array}$ & 7.04 & 9.54 & 9.25 & 10.70 \\
\hline $\mathrm{n}$ & 64 & 64 & 64 & 64 \\
\hline Std. dev. & 2.658 & 4.363 & 4.425 & 4.316 \\
\hline Std. error & .392 & .643 & .700 & .682 \\
\hline $\mathrm{r}$ & .847 & & .890 & \\
\hline $\mathrm{t}$ & -11.891 & & -2.931 & \\
\hline Df & 45 & & 39 & \\
\hline $\begin{array}{c}\text { Sig. } \\
\text { (2tailed) }\end{array}$ & $.000 *$ & & $.006 *$ & \\
\hline
\end{tabular}

*Significant difference

The writing test was marked upon 20. The test for significance for the Experimental Group's performance $(p<0.000)$ shows that subjects in this group have improved as far as essay writing is concerned. However, there is no significant difference in the performance of the Control Group $(\mathrm{p}<0.440)$, that is, the subjects who were not exposed to PBL have not made any significant improvement in their performance in essay writing, with the mean showing only a slight improvement.

\subsection{Overall Course Grades}

This section reports on the course marks of the subjects of both the PBL and non-PBL groups as well as the final grade distribution of the two groups. This section is pertinent, to see the outcome of the PBL approach which, as mentioned earlier, involved no explicit classroom instruction on the topics and students must "acquire" the syllabus on their own via problem solving. The issue is whether the students were able to pick up the major points of the course via the interactive self-learning, problem-based approach. To reiterate, the PBL groups received no explicit instruction on the course topics, while the control group carried on with the traditional approach, i.e., full lectures for the various topics.

At the end of the semester, both the PBL and non-PBL groups sat for the same final examination paper at the same time. The results of both groups are tabulated in Table 6.0.

Table 6. Distribution of Course Marks / Grades of PBL and non-PBL group

\begin{tabular}{|c|c|c|c|c|}
\hline Scores & \multicolumn{2}{c}{ PBL } & Non PBL \\
\hline \multicolumn{3}{|c}{ No of Students } & $\%$. & No of Students $\%$ \\
\hline $90-100$ & 0 & 0 & 2 & 3.2 \\
\hline $80-89$ & 4 & 6.3 & 5 & 7.8 \\
\hline $70-79$ & 10 & 15.6 & 6 & 9.5 \\
\hline $60-69$ & 19 & 29.7 & 16 & 25 \\
\hline $50-59$ & 26 & 40.6 & 22 & 34.5 \\
\hline $0-49$ & 5 & 7.8 & 13 & 20 \\
\hline
\end{tabular}

The results are presented according to the grades distribution to see how the students performed overall, directed by concerns whether or not they have missed anything in the course content, and compared to those of the control group. The grades appear to show that the non-PBL group did slightly better than the PBL group, with two students scoring between 90 to 100 . In the PBL group, no one scored between 90-100\%. However, the PBL group shows fewer students in the lower ranges, 31 for ranges 0-49 and 50-59, while the non-PBL group shows 35. This shows the weaker students might have benefited from the PBL approach more than the better students, as only 5 students got less marks in the course compared to 13 in the non-PBL group. Thus it has been concluded that the overall difference, however, is not large enough to show that the PBL approach did better than the non-PBL approach or vice versa.

Now the question is despite the minor difference in the results, did the PBL group acquire the course content? Since the results of the PBL group are similar to the non-PBL group, the answer is clear: the PBL group has acquired the course content in spite of minimal instruction. In fact, if we factor in the instructions that the non-PBL group received, the research would conclude that the PBL students had indeed done extremely well, as they did so on their own, without lecturer guidance. In addition to this, students from the PBL group had improved their language skills, compared to the non-PBL students. Therefore, the PBL method appears to be just as effective as the traditional method as far as content learning is concerned but more effective language acquisition required for professional engineering Undergraduates. 
One of the major questions is whether the PBL approach is better than the traditional lecture approach. Mavis and Wagner (2006) compared PBL to traditional lectures by documenting medical students' opinions of the two methods of instruction. Students wrote positively for both methods. PBL was seen as encouraging interpersonal skills, while lectures were seen as efficient in learning. Overall, students in Mavis and Wagner's (2006) study preferred PBL as it was enjoyable and successful in achieving other organization goals/skills and life-long learning skills. In the current study, we showed that the lack of instruction did not impede learning and students were able to learn what they were supposed to, as evidenced by the results of the final examinations. However, PBL is one teaching approach out of many that may be useful in the teaching of English, particularly to the professional engineering undergraduates, as it provides a meaningful reason and context to use the language.

The idea of self-learning is not novel. The seminal work of Lev Semenovich Vygotsky on the concept of Zone of Proximal Development (ZPD) was developed in late 1920s and ZPD is still being quoted frequently in current research, as seen in this example, which is: "the distance between the actual development level as determined by independent problem solving and the level of potential development as determined through problem solving under adult guidance or in collaboration with more capable peer" (Cole et al., 1980, p.86). The idea is that individuals learn best when collaborating with others, which also forms the basis of the PBL approach.

\section{CONCLUSION}

The overall results of the tests (cloze and written) show that the PBL group of the study were able to handle learning without explicit instruction and performed just as well as those in the traditional class. In terms of language, specifically in writing, students in the PBL group were also able to present their arguments in a more critical manner in the post-test essays and provided sufficient supporting material to illustrate their arguments. The non-PBL group, on the other hand, did not show marked differences in their language skills although they had the benefit of instructions and were guided throughout the semester by lectures. Given the "total" guidance, we expected students of the control group to perform better and show marked improvement in language skills. The reverse is true: the group that was left on their own did better. Thus, language lecturers or lecturers of other disciplines should take note of this and not be overly worried about sacrificing course content when using the PBL approach in their classes.

Suggestions for future PBL language classes include the following: (1) to fit in all the course modules, each output of group discussion need not always be presented; a comprehensive written report for a few of the modules would suffice; (2) the lecturer should assign more reading materials for each problem, for example, studying five different articles on a given topic which students may use to find solutions to their problems; and (3) use of Internet material should be accompanied by a printout of the site for the lecturer's perusal and to ensure the authenticity of students' work; (4) to consider the effects or role of the native language in students' discussions (Richards \& Rodgers, 2001).

As in all changes, a change from traditional-based lecture to the PBL approach would certainly face resistance from many sides. The first two are students who are already too familiar with the traditional lecture mode and thus would expect lectures, and teachers who are constrained by factors such as syllabus and time. However, Duch (1995) and the current study found that although there was initial resistance to the PBL approach, students eventually became highly motivated and, on another front, the lecturer will have to look forward to new possibilities presented by the PBL approach every semester, to create richer problems for the students to solve.

The concerns listed in this PBL study are also found in other language studies that use other approaches including the traditional approach: how to handle a large class, students using the native language, assessment, among others. Until now, there has not been much study on the issue of assessment of the PBL class. Most studies, such as this one, have focused on content (PBL versus non-PBL), although this is justifiable given that PBL is still in the experimental stage. Despite the usual problems one may encounter in handling the PBL method, it should still be tried out since the study has shown conclusively that students benefited from other positive effects of the approach in several ways: they communicated more, presented more critical arguments, while at the same time acquired the more course content. References

1. Allen, D. E., Duch, B. J., \& Groh, S. E. (1996). The power of problem-based learning in teaching introductory science courses. In L. Wilkerson, \& W.H. Gijselaers (Eds.), Bringing Problem-Based Learning to Higher Education: Theory and Practice (pp. 43-52). San Francisco: JosseyBass.

2. Albanese, M.A, \& Mitchell, S. (1993). Problem-based learning: a review of literature on its outcomes and implementation issues. Acad Med, 68(1):52-81. Retrieved August 30, 2009, from http://www.ncbi.nlm.nih.gov/pubmed/8447896.

3. Anonymous. (2009). Learner-centered classrooms, problem-based learning, and the construction of understanding and meaning by students. Retrieved August 31, 2010, from http:// www.ncrel.org/sdrs/ areas /issues/content/cntareas/ science/ sc3l earn.htm.

4. Anton, P. (1990). Student perceptions of problemsolving activities in an ESL classroom. TESOL Quarterly, 23, 3(1), 14-17.

5. Bannett, R.E. (1993). On the meanings of constructed response. In R. Bennett \& W. Wards(Eds.), Construction versuschoice in cognitive measurement: Issues in constructed response,performing testing and portfolio assessment. (PP.1-28). Hillsdale, NJ: Lawrence Earlbaum.

6. Barrows, H. S., \& Tamblyn, R. M. (1980). Problembased learning: An approach to medical education. New York: Springer Pub. Co. 
7. Barrows, H.S. (2000). Problem based learning applied to medical education. Springfield IL:Southern Illinois University Press.

8. Bloom B.S. (1956). Bloom's taxonomy of learning domains: The three types of learning.Retrieved December 30, 2009 from http://www.nwlink.Com/ Donclark /hrd/ bloom.html \# types

9. Boud, D. J., \& Feletti, G. I. (1994). Introduction. In D. J. Boud, \& G. I. Feletti (Eds.), The challenge of problembased learning. London: Kogan Page.

10. Cohen, E.G. (1994). Restructuring the classroom: Conditions for productive small groups.Review of Educational Research, 64, 1-35

11. Dochy, F., Segers, M., Van Den Bossche, P., \&Gijbels, D. (2003). Effects of problem based learning: A metaanalysis. Learning and instruction, 13, 533-568.

12. Duch, Barbara J. (1995). The power of problem-based learning. A Newsletter of the Center for Teaching Effectiveness, January 1995. Retrieved October 20, 2004 from http://www.udel.edu/pbl/cte/spr96bisc2.html

13. Gallagher, S., Stepien, W., Sher, B., \& Workman, D. (1995). Implementing problem-based learning in science classrooms. School Science and Mathematics, 95, 136-146.

14. Hmelo- Silver, C.E. (1998). Problem based learning: Effects on the early acquisition of cognitiveskills in medicine. Journal of the learning sciences, 7, 173-208. 15. Hmelo-Silver, C.E. (2004). Problem based learning: What and how students learn? EducationalPsychology Review, 16, 235-266.

16. Hmelo-Silver, C, E. (2009). What do we know about problem based learning? Current status andfuture prospects. What are we learning about learning: 2nd International PBL Symposium,2-19. Singapore: Republic Polytechnic.

17. Herreid, C.F. (2003). The death of problem-based learning? Journal of College ScienceTeaching. 32 (6), 364-366.

18. Lieux, E., \& Duch, B. (1995, February). Strategies for teaching quantity food production andservice: Lecture methodversus problem based learning. In C. Kohnke \& R. Maize (Eds.), Back tothe future: Food service managementeducation in the 21 st century.

Proceedings of the $18^{\text {th }}$ biennial conference of Food Service Management EducatorsPractice Group of ADA, Olive Branch, MS.

19. Mavis, B. E., \& Wagner, D. P. (2006). Comparing problem-based learning and lectures. Academic Exchange Quarterly, 10(4).

20. Merrill, M.D. (2002). A pebble-in-the-pond model for instructional design. Performance Improvement41(7),39-44. Retrieved August 21, 2009, from http://www.spi.rg/df/errill. pdf.

21. Ommundsen, Peter. (2001). Problem-based learning in biology with 20 case examples. RetrievedAugust 31, 2009 from http:// capewest.Ca / pbl.html 